\title{
Effect of the Morphology and Structure on the Microwave Absorbing Properties of Multiwalled Carbon Nanotube Filled Epoxy Resin Nanocomposites
}

\author{
Valdirene Aparecida da Silva ${ }^{a, b *} \oplus^{0}$, Mirabel Cerqueira Rezende ${ }^{a, c}$ \\ anstituto Tecnológico de Aeronáutica - ITA, Praça Marechal Eduardo Gomes, 50, São José dos \\ Campos, SP, Brasil \\ ${ }^{b}$ Universidade do Vale do Paraíba - UNIVAP, Av. Shishima Hifumi, 2911, São José dos Campos, SP, \\ Brasil \\ 'Instituto de Ciência e Tecnologia - ICT, Universidade Federal de São Paulo - UNIFESP, Rua Talim, \\ 330, São José dos Campos, SP, Brasil
}

Received: October 31, 2017; Revised: March 06, 2018; Accepted: June 08, 2018

\begin{abstract}
The current research shows the effect of structural and morphological differences of multilayer carbon nanotubes (CNT) on radar absorbing materials (RAM) performance. Two CNT samples, from different manufacturers, had their morphological and structural aspects investigated by XRD, SEM and SEM-FEG analyses. CNT/epoxy resin based nanostructured composites were prepared and characterized by reflectivity measurements in the X-band. SEM results show the formation of agglomerates in the composites and the XRD patterns show structural differences between the two CNT samples. The best RAM performance $(-25 \mathrm{~dB})$ was determined for the nanocomposite based on the CNT with the smallest stacking layers $(\mathrm{Lc}=26.9 \AA)$ associated to the longest length of nanofilament $(10-20 \mu \mathrm{m})$. This characteristic can have contributed to the formation of an interconnected network in the composite favoring electrical conductivity and dielectric properties, with the consequent increase of the wave attenuation.
\end{abstract}

Keywords: Carbon nanotubes, Radar absorbing materials, Reflectivity, XRD, SEM.

\section{Introduction}

In recent years the electromagnetic pollution is increasing due to the increased presence of microwaves in the environment. This situation is due to the increased use of electronic devices in civilian and military areas. In function of this scenario, studies involving radar absorbing materials (RAM), named also as electromagnetic radiation absorbing materials or microwave absorber materials, have been of great technological importance and have attracted the attention of researchers worldwide ${ }^{1,2}$.

RAM are materials that promote the electromagnetic wave attenuation in the microwave range reducing the radiation of the incident wave and dissipating the absorbed energy as heat. These materials are constituted by compounds that promote energy losses of the electromagnetic radiation in certain frequency bands. The internal mechanisms of losses can involve magnetic or dielectric characteristics. The loss mechanisms may be physical, chemical or both simultaneously. Nowadays, researches involving RAM cover the frequency range from 1 to $100 \mathrm{GHz}^{3,4,5}$.

Nanostructured materials have been extensively investigated as RAM. The use of carbon nanotubes (CNT) as conductive filler has been widely studied in RAM processing due to their physical and chemical properties. CNT exhibit high mechanical resistance, which may vary from 10-100 GPa with module up to $1 \mathrm{TPa}$, reduced density (10-1315 g.m $\left.\mathrm{m}^{-3}\right)$ according to the number of walls of and excellent electrical $\left(10^{4}-10^{6}{\mathrm{~S} . \mathrm{cm}^{-1}}^{-1}\right)$ and thermal properties $\left(3000-6000 \mathrm{mK} . \mathrm{W}^{-1}\right)$. CNT cylinders may have open or closed ends ${ }^{6,7,8,9,10}$. Studies have shown that CNT can perform well in the microwave attenuation when incorporated in polymeric matrices and in multilayer structures ${ }^{9,10,11}$.

The characteristics of CNT, such as type, length, diameter, density, surface, purity, and the tendency to form agglomerates depend on their synthesis conditions. Besides the CNT characteristics, the concentration and the quality of dispersion in polymeric matrices combined with the thickness of absorber may confer a good performance for the processed RAM. Studies show that CNT with few walls and greater length may confer higher attenuation values of the electromagnetic wave due to the dielectric properties conferred to the nanocomposite ${ }^{11,12}$. So, the use of different both CNT and polymeric matrices in the nanostructured composite processing can result in RAM with different characteristics and applications ${ }^{12}$.

George et al. show that low concentrations of multiwalled CNT $(0.086 \mathrm{wt} \%)$ in natural rubber based nanostructured composites confer high values of electrical conductivity and dielectric constants due to the formation of an interconnected network. In this case, improved mechanical properties are also observed with increased tensile strength, elastic modulus and tear strength ${ }^{13}$. 
In this study, nanostructured composites based on two different multilayers CNT filled in epoxy resin were processed. X-ray diffraction (XRD) evaluated the CNT structural characteristics. Morphological characteristics of materials were evaluated using scanning electron microscopy (SEM) and scanning electron microscopy with field emission (SEM-FEG). The electromagnetic characterization of CNT/ epoxy resin nanocomposites was performed considering reflectivity measurements in the frequency range of 8.2 12.4 GHz (X-band).

\section{Experimental}

\subsection{Materials}

Nanostructured composite samples were prepared by using two samples of multiwall CNT, non-functionalized, from different suppliers. The first one is from Bayer Co. Ltd., Baytubes_C150P code, named in this study of CNT-B, with diameter varying between 13 and $16 \mathrm{~nm}$, and 3-15 walls, length $>1 \mu \mathrm{m}$, density of $120-170 \mathrm{~kg} / \mathrm{m}^{3}$ and purity $\geq$ $95 \%{ }^{14}$. The second sample, named CNT-K, is from Hanwha Chemical Company, CM-95, with a diameter of 10-15 nm, length $10-20 \mu \mathrm{m}$, density of $50-100 \mathrm{~kg} / \mathrm{m}^{3}$ and purity of $93-97 \%{ }^{15}$. The two CNT samples were incorporated into a bicomponent epoxy resin matrix from Hexion, code Epikote ${ }^{\mathrm{TM}}$ MGS $^{\circledR}$ L135, using the hardener 137 Hexion $^{\mathrm{TM}}$, attending the relation $1: 1$, in weight.

The nanostructured composites were prepared containing $0.1 ; 0.5$ and $1.0 \mathrm{wt} \%$ of CNT-K and $0.1 ; 0.5 ; 1.0 ; 1.5$ and $2.0 \mathrm{wt} \%$ of CNT-B in epoxy resin. Table 1 presents the formulations prepared. CNT-K samples with 1.5 and $2.0 \mathrm{wt} \%$ were not prepared because of the difficulty of homogenization.

CNT samples were initially dispersed in the epoxy resin prior to the addition of hardener. To achieve a homogeneous dispersion of the CNT in epoxy matrix it was used an ultrasound sonicator type, Sonifier Sonics Vibra-Cell VC 505-VC 750. The dispersion was performed for $10 \mathrm{~min}$ using $25 \%$ of its maximum amplitude $(750 \mathrm{~W}, 20 \mathrm{kHz})$. After homogenization, the resin curing was promoted

Table 1. Formulations of nanocomposites based on CNT-K and CNT-B filled in epoxy resin.

\begin{tabular}{ccc}
\hline $\begin{array}{c}\text { Nanocomposites } \\
\text { CNT/epoxy resin }\end{array}$ & $\begin{array}{c}\text { CNT concentration } \\
(\mathrm{wt} \%)\end{array}$ & Code \\
\hline CNT-K & 0.1 & CNT-K1 \\
CNT-K & 0.5 & CNT-K5 \\
CNT-K & 1.0 & CNT-K10 \\
CNT-B & 0.1 & CNT-B1 \\
CNT-B & 0.5 & CNT-B5 \\
CNT-B & 1.0 & CNT-B10 \\
CNT-B & 1.5 & CNT-B15 \\
CNT-B & 2.0 & CNT-B20 \\
\hline
\end{tabular}

by the addition of hardener. The cure took place at room temperature and atmospheric pressure for $8 \mathrm{~h}$. Rectangular specimens (22.9 $\mathrm{mm} \times 10.2 \mathrm{~mm}$ and thickness of $9.0 \mathrm{~mm}$ ) were prepared. These dimensions correspond to the size of the sample-holder used in electromagnetic characterization.

\subsection{Characterization}

$\mathrm{X}$-ray diffraction (XRD) analyses were performed to identify the crystallographic order of the two CNT samples. An X-ray diffractometer from Shimadzu, XRD-6000 model, using $\mathrm{Cu}-\mathrm{Ka}(\lambda=1.54439 \AA)$ was used. The $2 \theta$ parameter varied between $10^{\circ}$ and $80^{\circ}$. The CNT/epoxy resin based nanostructured composites were analyzed in a Philips equipment, model Xpert PRO 3060-40 kV and $45 \mathrm{~mA}$, using $\mathrm{Cu}-\mathrm{Ka}(\lambda=1.54439 \AA)$ and $2 \theta$ between $10^{\circ}$ and $80^{\circ}$.

The dimensions of the carbon material crystallites can be expressed by the average stack height $\left(\mathrm{L}_{\mathrm{c}}\right.$ or $\left.\mathrm{L}_{002}\right)$ and the average length of the layers or crystallites $\left(\mathrm{L}_{\mathrm{a}}\right)$ (Figure 1). For crystallites that did not suffer distortion or strain on the network, these measures can be calculated by the expression of Scherrer (1918). The stacking height was obtained from the Scherrer equation, expressed by Equation $1^{16}$.

$$
L c=\frac{K \lambda}{\beta_{002} \cos \theta_{002}}
$$

where: $\lambda$ is the wavelength of the $\mathrm{X}$-ray beam (for $\mathrm{Cu}$ tube, $\mathrm{K}_{\alpha}=1.54 \AA$ ); $\mathrm{K}$ is a proportionality constant and depends on the particle shape, and ranges from 0.84 to 0.89 . In the case of the geometry of the crystallites is not knowing, assume $\mathrm{K}=0.89 . \beta_{002}$ or $\mathrm{L}_{1 / 2}$ is the width at half peak height (002) and $\theta$ is the diffraction angle. The relationship between the diffraction interplanar angles and the distance between the set of parallel atomic planes of a crystal lattice $\left(\mathrm{d}_{\mathrm{hkl}}\right.$ - interplanar distance) is given by Bragg equation, Equation $2^{16}$.

$$
2 d_{h k l}=\frac{\lambda}{(2 \operatorname{sen} \theta)}
$$

Scanning electron microscopy (SEM) analyses were carried out to assess the morphology of CNT samples and also the CNT dispersion in epoxy resin. For this, it was used an equipment LEO, model $435 \mathrm{Vpi}$. The samples was fixed on aluminum stubs and coated with a thin film of

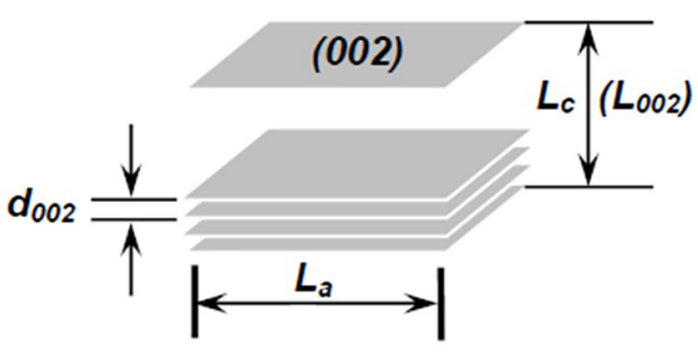

Figure 1. Schematic of a graphitic crystallite with their crystallographic parameters $^{16}$ 
gold, in order to ensure the electrical conductivity of the surfaces. Scanning electron microscopy of high resolution with field emission (SEM-FEG) was also performed by using an equipment TESCAN Oxford Instrument X-man, with magnifications ranging from 100000 to 500000 times. The voltage and working distance were $20 \mathrm{kV}$ and $1.5 \mathrm{~mm}$, respectively.

The electromagnetic characterization of nanostructured composites was performed in the frequency range of 8.2 to $12.4 \mathrm{GHz}$ by means of reflectivity measurements. This characterization was carry out in a rectangular waveguide using the transmission line method, also called transmission/ reflection method of guided waves ${ }^{17}$. These analyses were performed on a vector analyzer networks, from HewlettPackard, 8510C model, fitted to a rectangular waveguide HP, $\mathrm{X} 752 \mathrm{C}$ model for the X-band. A metal plate of aluminum was used in the back of the specimens as reference of a reflector material $(100 \%)$, as illustrated in Figure 2.

\section{Results and Discussion}

\subsection{Morphological characterization}

SEM and SEM-FEG analyses were conducted to characterize the morphology of CNT samples and to know the dispersion of CNT in the epoxy resin aiming to support the understanding of electromagnetic behavior of the nanostructured composite processed. Figure 3 shows SEM-FEG micrographs of neat CNT-B and CNT-K, with magnification of $100000 \mathrm{x}, 350000 \mathrm{x}$ and 500000x. The images show, as expected, that the CNT samples are filaments, curved and interlaced, forming CNTs tangles of filaments with lengths exceeding $2 \mu \mathrm{m}$. The images show the CNT-B entangled with diameters ranging from 10 to $30 \mathrm{~nm}$ (Figure 3a,b,c). Bright spots are also observable and attributed to the presence of residue of iron particles, used in the CNT synthesis (Figure 3a,b).

Figure $3 \mathrm{~d}, \mathrm{e}, \mathrm{f}$ shows images of entangled CNT-K with diameters varying from 20 to $23 \mathrm{~nm}$. It is also observed that these CNT are longer and thinner and with a higher amount of impurities (Fe particles).

In general, the micrographs show different amounts of nanofilaments in the two CNT samples that keep together by the inherent presence of van der Waals interactions in this type of nanofiller. Depending on the CNT agglomeration tendency, its dispersion in the polymer matrix is difficult

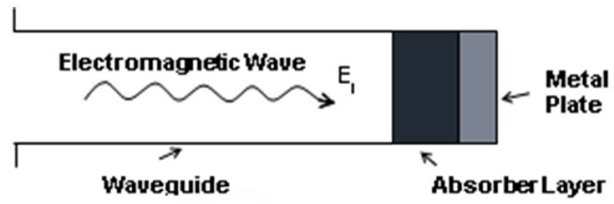

Figure 2. Schematic of a transmission-reflection line method in a waveguide with a sample characterized with a metal plate (Ei incident wave, Ea - absorbed energy) resulting in the formation of agglomerates, which are observed as small islands in polymer matrix, as observed in literature ${ }^{18,19}$.

Figure 3a,d of CNT-B and CNT-K with magnification of 100000x shows the presence of tangles of CNTs with varied diameters. Figure $3 \mathrm{~b}$ shows the presence of thinner filaments of CNT-K than those observed for CNT-B (Figure 3e).

Figure $4 a, b, c$ shows representative images of CNT-B in epoxy resin in the concentrations of $0.1 ; 0.5$, and $1.0 \mathrm{wt} \%$. Figure 4d,e,f is representative of CNT-K based nanocomposites. Images of the formulations containing 1.5 and $2.0 \mathrm{wt} \%$ of CNT-B are not shown because these are very similar to those seen in Figure 4e.

Besides the experimental efforts to decrease the tendency of agglomeration of the used CNT in the epoxy resin, SEM analyses show the presence of them in the prepared nanocomposites (Figure 4). Interconnected CNT nanofilaments formed regions similar to islands in the epoxy resin matrix. This behavior is in agreement with the data described in literature ${ }^{20,21,22,23,24}$, where different experimental procedures studied did not prevent the presence of at least some CNT agglomerates in the nanocomposite. In Figure 4 it is observed that within the agglomerate there is a homogeneous distribution of the nanofilaments. In the case of CNT-K based nanocomposite it is observed the presence of areas richer in resin, even in higher concentrations of CNT, suggesting the formation of more compact agglomerates (Figure 4d,e).

\subsection{Structural characterization}

Figure 5 shows the XRD patterns of CNT-K and CNT-B samples. The peak related to the plane (002), at $26^{\circ}$, is characteristic of graphitic materials and attributed to the distance between the concentric graphene sheets of multiwalled CNT. The interlayer distance parameter can be calculated by Bragg's law ${ }^{20,25,26,27}$. The intensity and width of peak are related to the number of layers, the variations in interlayer distance, the content network distortion and also to the orientation of CNT. In addition to the peak (002), around $26^{\circ}$, a family of peaks (hk0) is found, assigned with the network of hexagons (like a "chicken wire") of graphene sheets. These reflections are attributed to the structure of individual layer of graphene walls. Peaks (hk0) present asymmetrically due to the curvature of $\mathrm{CNT}^{25,26,27}$.

Figure 5 shows two long and narrow peaks centered around $26^{\circ}$. Those correspond to the plane of reflections (002) and two broad and diffuse bands at $43^{\circ}$, attributed to contributions of the plans (100) and (101). These bands are characteristics of turbostratic structure of carbon materials ${ }^{27}$.

The interplanar distances of the peaks $\left(\mathrm{d}_{002}\right)$ were calculated from Bragg's Law, resulting in $3.51 \AA$ and 3.58 $\AA$ for CNT-B and CNT-K samples, respectively. These interplanar distances are relatively close for the two CNT samples, with the trend of better ordering for CNT-B, where the theoretical $\mathrm{d}_{002}$ for the graphite is $3.3354 \AA^{28}$. 


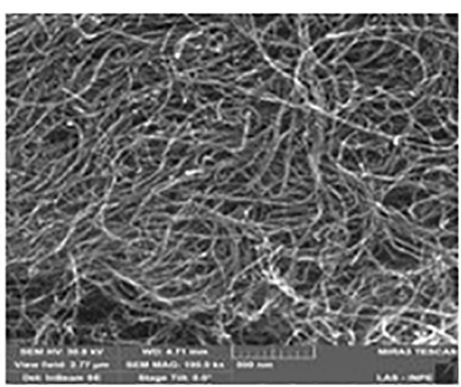

(a)

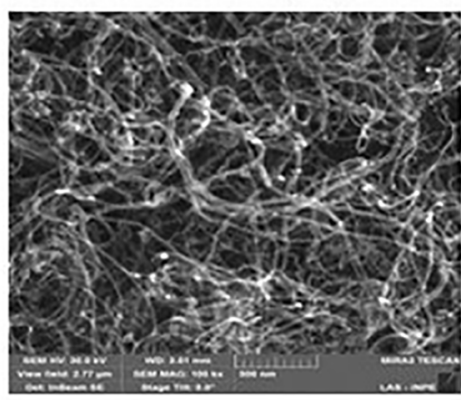

(d)

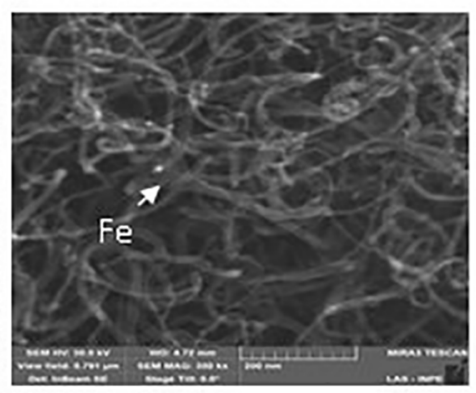

(b)

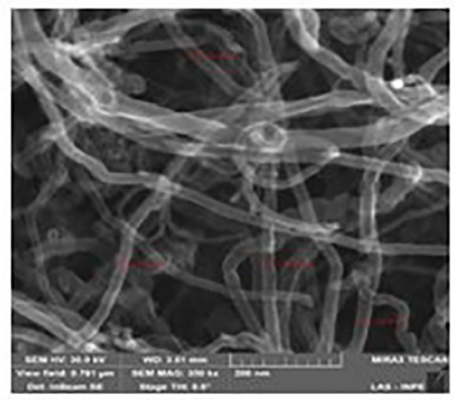

(e)

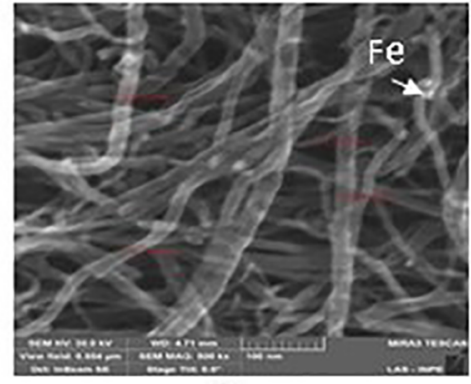

(c)

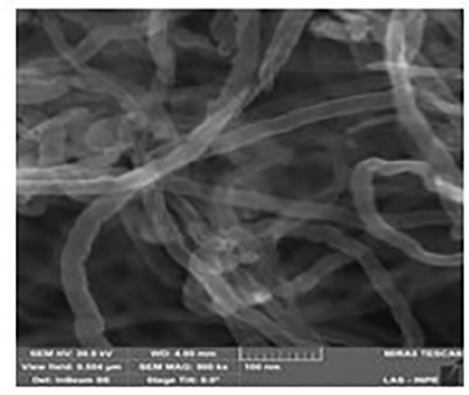

(f)

Figure 3. SEM-FEG of CNT-B: (a) 100000x, (b) 350000x, (c) 500000x, and CNT-K: (d) 100000x, (e) 350000x, (f) 500000x

The full width at half maximum (FWHM) of the peak (002) may be used to evaluate the degree of ordering of CNT samples. In this context, the smallest value of FWHM of the CNT-B $(0.044 \mathrm{rad})$ shows more clearly that this sample presents a better structural ordering than CNT-K $(0.052 \mathrm{rad})$, i.e. narrower peaks refer to more well-ordered crystalline domains.

For Lc parameter it is observed the same trend, which represents the stacking height of graphitic structures or, in the case of CNT, the CNT-wall thickness. In the case of CNT-B, the value of Lc is $32.2 \AA$ and for CNT-K, Lc is $26.9 \AA$. From these results it can be considered that the CNT-B presents a better structural ordering than CNT-K. The relation between the parameters Lc and $\mathrm{d}_{002}$ allows estimating that the CNT-B has around 9 layers and the CNT-K approximately 7 layers.

Table 2 shows the FWHM of the peaks at $26^{\circ}$ (plane (002)), the interlayer distance $\left(\mathrm{d}_{002}\right)$, the average height of crystallite $(\mathrm{Lc})$ and the number of layers calculated from the ratio $L c / d_{002}$, for the two CNT samples studied.

Figure 6 shows the X-ray diffraction patterns of nanostructured composites with different concentrations of $\mathrm{CNT}$ in epoxy resin. The analysis of this figure shows two distinct peaks, one at around $20^{\circ}$ for both CNT-B/epoxy resin and CNT-K/epoxy resin and a second peak at $43^{\circ}$ for both nanocomposite samples. Comparing these XRD patterns to those presented in Figure 5 it is verified a shift from the first peak at $26^{\circ}$ to about $20^{\circ}$. The second contribution, at $43^{\circ}$, does not present displacement in relation to those observed in Figure 5. This result suggests the presence of interfacial interactions between CNT and epoxy resin matrix which contributed to the displacement of the peak from $26^{\circ}$ to $20^{\circ}$. According to the literature ${ }^{28}$, it is possible the occurrence of epoxy resin intercalation between the graphene layers of CNT with the displacement of $2 \theta$ to smaller angles.

The analysis of these parameters shows an increase of the interlayer distance of CNT in the nanostructured composites. This increase is attributed to the interaction of smaller molar mass fractions of epoxy resin with CNT, resulting in the intercalation of small molecules between the layers of CNT structure. The literature mentions similar behavior for CNT in polymeric composites ${ }^{28,29,30}$. The proposed CNT/epoxy resin interaction can be considered interesting when a good interface between the two components is desired, although this behavior contributes to increase the interlayer distance. So, the XRD patterns of the nanocomposites show that the epoxy resin affected CNT microstructure probably due to the intercalation of resin in the CNT microstructure resulting in a good CNT-polymeric matrix interaction.

Figure 6 shows that the increase of CNT concentration in the epoxy resin matrix contributed to increase the peak intensity in $2 \theta=\sim 20^{\circ}$. The CNT-B based composite shows that there is an increase until the concentration of $1.5 \mathrm{wt} \%$ (Figure 6a). And in the case of CNT-K based composite the increase occurs until $0.5 \mathrm{wt} \%$ of CNT (Figure $6 \mathrm{~b}$ ). This behavior is attributed to the contribution of larger crystalline portion of CNT-B in epoxy resin. Table 3 summarizes the crystallographic parameters obtained from XRD patterns presented in Figure 6. The FWHM increase, compared to the 


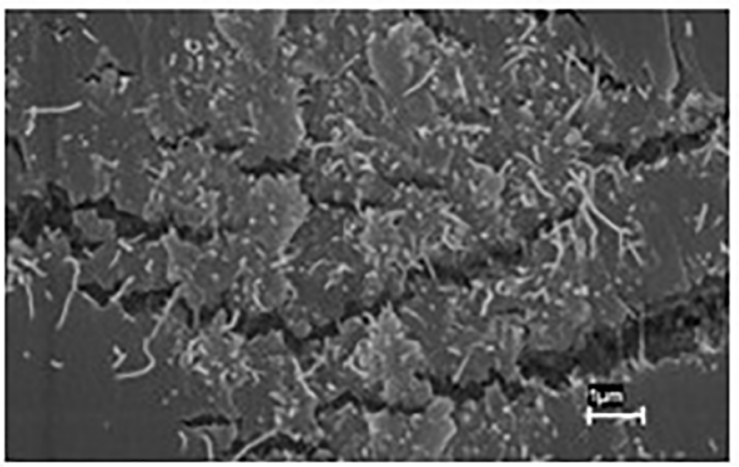

(a)

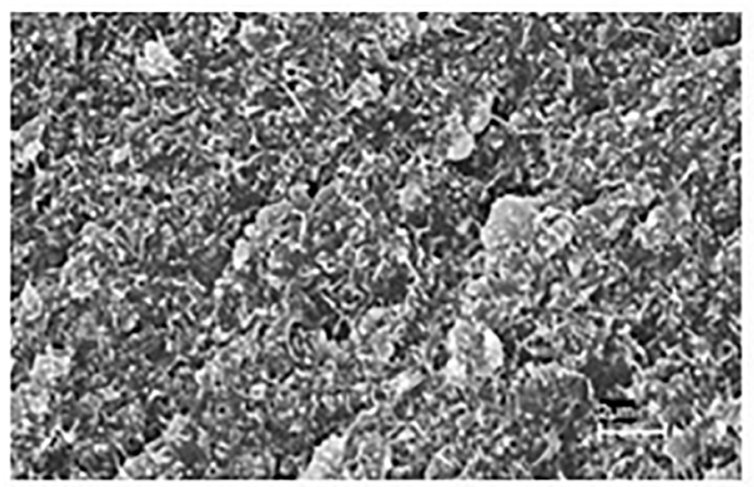

(c)

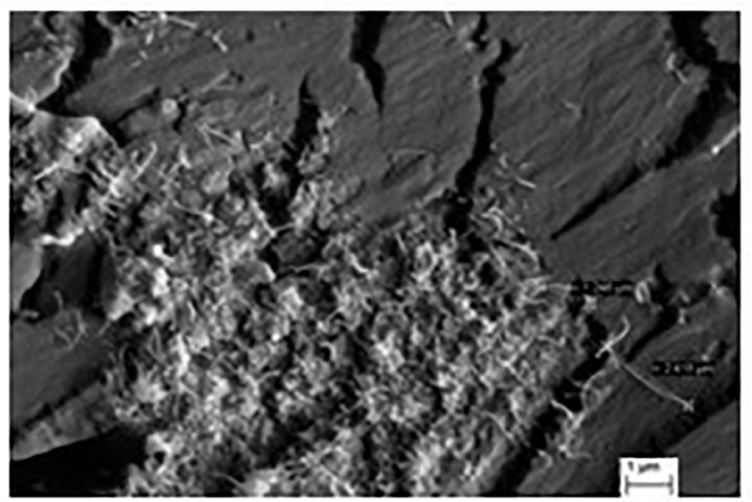

(e)

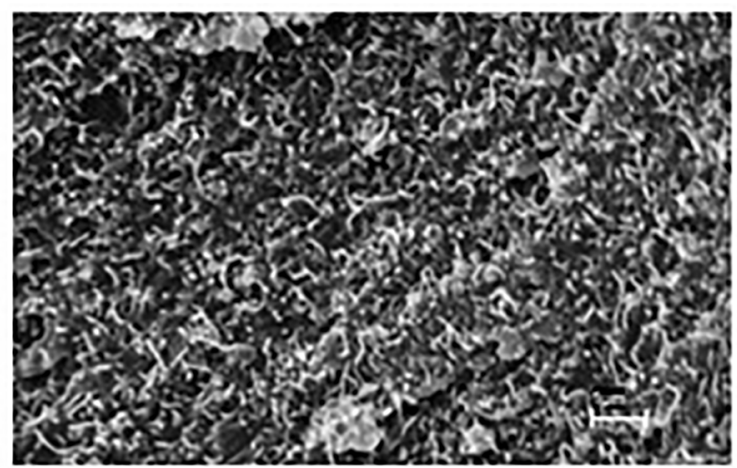

(b)

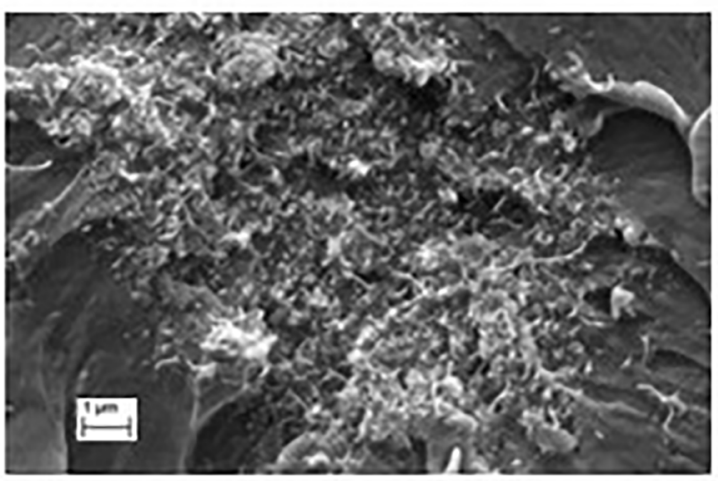

(d)

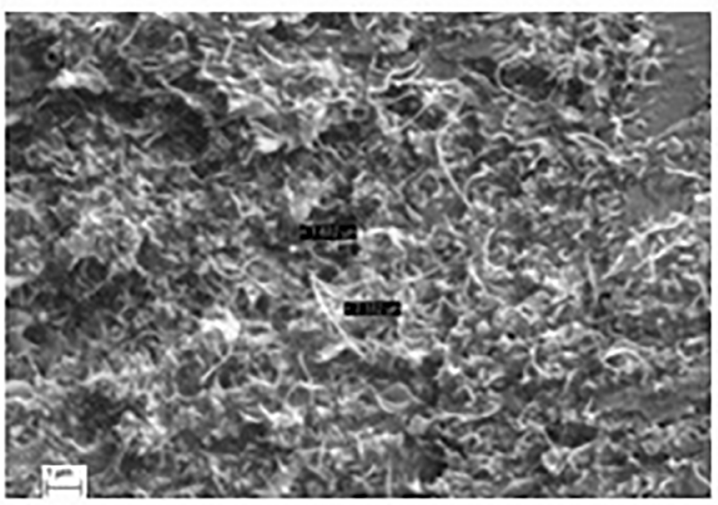

(f)

Figure 4. SEM of CNT/epoxy resin composites. CNT-B contents (wt\%): (a) 0.1, (b) 0.5, (c) 1.0 and CNT-K (wt \%): (d) 0.1 , (e) 0.5 , (f) 1.0

data of Table 2, confirms the decrease of CNT crystallographic ordering in epoxy resin-nanocomposites.

\subsection{Electromagnetic characterization}

Considering an electromagnetic wave launched on the surface of a material, reflectivity measurements evaluate how much of the incident wave is attenuated by the material, measuring, for this, the reflected energy from the material's surface. The reflection reduction is compared with a perfect reflector, in the present case, an aluminum metal plate, considered a material $100 \%$ reflector, attenuating $0 \mathrm{~dB}^{17}$.

An ideal absorber material must satisfy two conditions. First, the impedance matching between the free space and the material's surface aiming reduce multiple reflections of the incident electromagnetic wave on the material's surface. And second, an absorber must attenuate the maximum intensity of the incident electromagnetic wave, by dielectric and/or magnetic mechanisms of losses. Thus, the RAM 


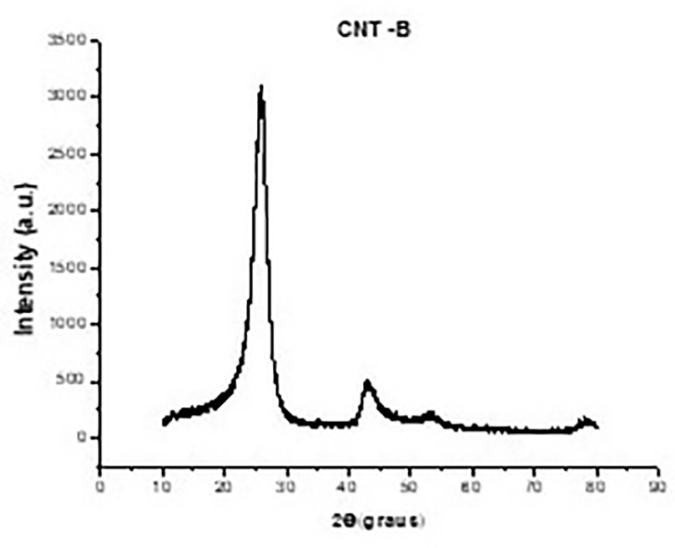

(a)

Figure 5. XRD patterns of (a) CNT-B and (b) CNT-K

Table 2. Crystallographic parameters (FWHM, $\mathrm{d}_{002}$, Lc and number of layers) of CNT-B and CNT-K samples.

\begin{tabular}{lccccc}
\hline Samples & $2 \theta\left({ }^{\circ}\right)$ & $\begin{array}{c}\text { FWHM } \\
(\mathrm{rad})\end{array}$ & $\begin{array}{c}\mathrm{d}_{002} \\
(\AA)\end{array}$ & $\begin{array}{c}\text { Lc } \\
(\AA)\end{array}$ & $\begin{array}{c}\text { Median } \\
\text { number } \\
\text { of } \\
\text { layers }\end{array}$ \\
\hline CNT-B & $26 / 43$ & 0.044 & 3.51 & 32.2 & 9 \\
CNT-K & $26 / 43$ & 0.052 & 3.58 & 26.9 & 7 \\
\hline
\end{tabular}

need to present suitable values of electrical and dielectric parameters $^{30,31}$.

CNT present promising dielectric characteristics to be used as microwave absorber ${ }^{32}$, and CNT based RAM are classified as dielectric absorber where the losses occur mainly by polarization effect and electric conductivity ${ }^{33,34,35}$.

The literature cites that the CNT in the polymer matrix promotes the presence of a greater number of interfaces which favor the interfacial polarization presence. This phenomenon results in both accumulation of charges and higher orientation of dipoles, which promote the attenuation of incident wave, besides possible ohmic losses ${ }^{31,33,35}$. Some researchers mention yet the dependence of the electromagnetic wave attenuation in function of frequency band, suggesting that in lower frequencies the molecules and electrons have enough time for promoting any energy loss mechanism. Already in higher frequencies the time is not enough to promote any phenomena ${ }^{36,37}$.

Figure 7 shows the reflectivity curves of the composites prepared in this study, assessed by means of transmission line technique in waveguide. All samples were experimentally measured with $9.0 \mathrm{~mm}$-thickness. The black line located at $0 \mathrm{~dB}$ corresponds to the evaluation of the reference material, i.e., the aluminum plate. Superimposed on this line we have the response related to the neat (pure) epoxy resin matrix, without CNT addition. The overlap of aluminum plate and neat epoxy resin reflectivity curves shows that the studied polymeric matrix is transparent to microwaves in X-band, not interfering in the CNT behavior into the nanocomposites.

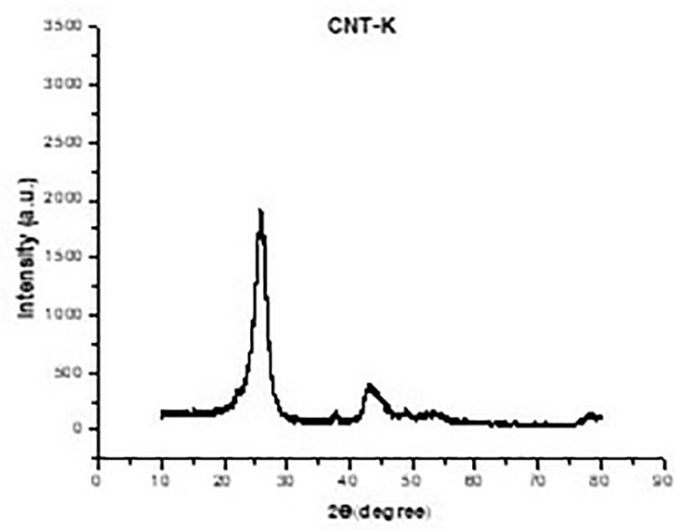

(b)

Figure 7a shows that the CNT-B composite samples present lower performance in the frequency band evaluated, when compared to Figure 7b. The composite CNT-B1, CNT-B5, CNT-B15 and CNT-B20 have reflectivity values between -1 $\mathrm{dB}$ and $-1.5 \mathrm{~dB}$ in the frequency range evaluated. Already the CNT-B10 sample presents a resonance behavior at the end of the frequency range studied, $12.4 \mathrm{GHz}$, reaching an attenuation value of $-7 \mathrm{~dB}$, or attenuation of incident wave of $80 \%$. Still, it is observed that the CNT-B10/epoxy resin composite shows the tendency of better attenuation behavior in frequencies above $12.4 \mathrm{GHz}$. XRD analyses showed that the CNT-B samples presented the best structural arrangement, but, according to the suppliers, compared to the CNT-K, the CNT-B has a shorter length which may disadvantage the formation of more interconnected networks in the nanocomposite, disfavoring the impedance matching and electrical and dielectric losses.

Figure $7 \mathrm{~b}$ shows the reflectivity curves of the CNT-K based nanostructured composites. The reflectivity values measured show attenuation values up of $-25 \mathrm{~dB}$ and $-10 \mathrm{~dB}$ for the formulations with 0.5 and $1.0 \mathrm{wt} \%$ of CNT-K, respectively. These measured values indicate that the electromagnetic wave incident on the material was attenuated around $99.7 \%$ and $90 \%$ in the frequency of $11 \mathrm{GHz}$ and $9.5 \mathrm{GHz}$, respectively. The composite with $0.1 \mathrm{wt} \%$ of CNT-K has a maximum attenuation of $-3 \mathrm{~dB}$ at $12.4 \mathrm{GHz}$, corresponding to $50 \%$ of attenuation. The curve presented by $0.1 \mathrm{wt} \%-\mathrm{CNT}-\mathrm{K}$ based sample shows that this composite presents a better performance in frequencies above $12.4 \mathrm{GHz}$. This trend is reported in the literature ${ }^{30,38}$.

An interesting feature observed for the composites with 0.5 and $1.0 \mathrm{wt} \%$ of CNT-K is that these samples behave as resonant absorbers, i.e. attenuate the incident wave in narrower frequency range. These composites present maximum resonance peaks at $11 \mathrm{GHz}$ and $9.5 \mathrm{GHz}$, respectively. This behavior is related to the wave phase cancelling phenomenon ( $\lambda / 4$ effect) of the wave that propagated into the material. 


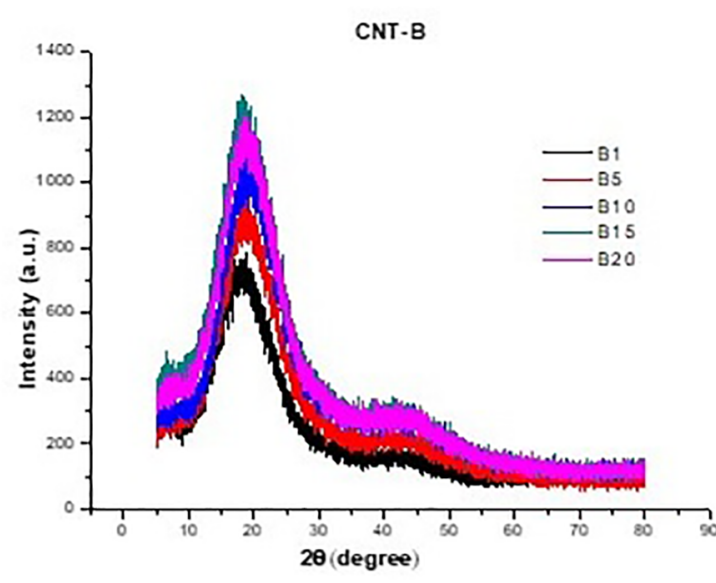

(a)

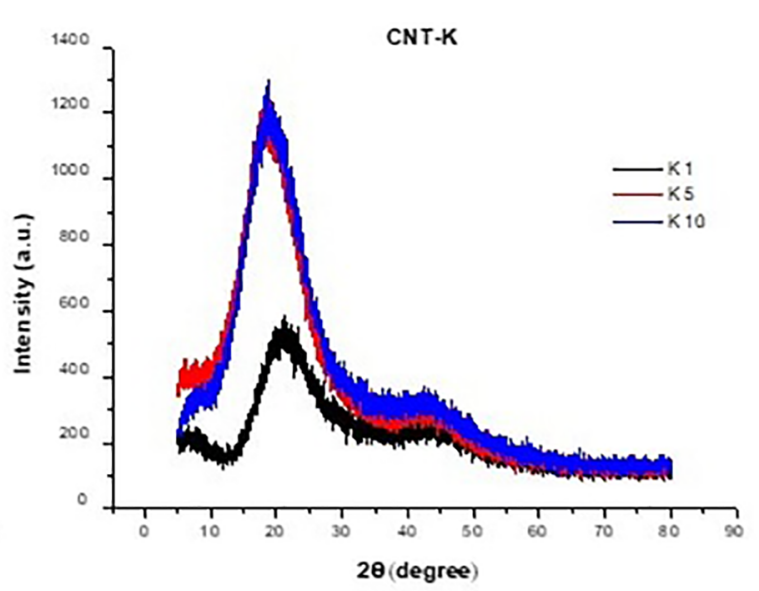

(b)

Figure 6. XRD patterns of nanostructured composites

Table 3. Crystallographic parameters $\left(2 \theta, \mathrm{L}_{1 / 2}, \mathrm{~d}_{002}\right)$ of nanostructured composites.

\begin{tabular}{lccc}
\hline Sample & $2 \theta\left(^{\circ}\right)$ & $\begin{array}{c}\text { FWHM } \\
(\mathrm{rad})\end{array}$ & $\begin{array}{l}\mathrm{d}_{002} \\
(\AA)\end{array}$ \\
\hline CNT-B10/epoxy resin & $20 / 43$ & 0.17 & 8.97 \\
CNT-K10/epoxy resin & $21 / 43$ & 0.16 & 9.85 \\
\hline
\end{tabular}

Considering that the wave propagates into the material when the adequate impedance matching is promoted. In the present study this condition was found for any CNT concentration studied ${ }^{39}$.

The sample processed with $0.5 \mathrm{wt} \%$ of CNT-K shows a better attenuation performance of the electromagnetic wave when compared to the specimen with $1.0 \mathrm{wt} \%$ of CNT. This behavior is attributed to a more appropriate impedance matching between the medium in which the wave propagates (free space) and the first surface of specimen. This condition favors the wave propagation through the

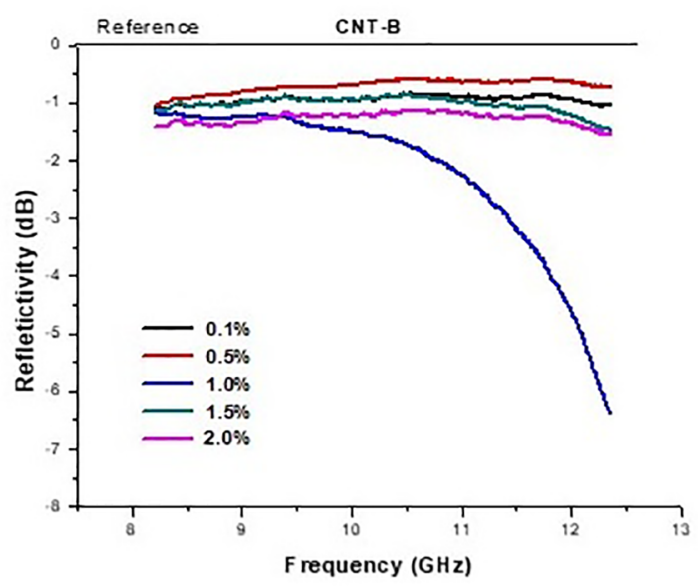

(a) material and its attenuation. The literature mentions that the wave attenuation by a CNT based RAM can be promoted by a good interface between the CNT and epoxy resin that promotes interfacial polarization ${ }^{31,35}$. This phenomenon in the presence of multiwalled CNT is generally affected by the structural characteristics of these nanofillers. Electrical conductivity combined with the wave phase cancelling phenomenon promoted also the wave attenuation. This consideration is in agreement with the literature ${ }^{32,33,34,37}$. Thus, different formulations lead to different impedance matching values, which may or not lead to the attenuation of incident electromagnetic radiation ${ }^{34}$.

According to literature ${ }^{40}$, the configuration and spatial orientation of CNT are considered the main parameters that may influence the electrical conductivity of this filler. In this case, it should be considered that a good interaction between polymer matrix and CNT may reduce the electrical conductivity of the processed nanocomposite. However, this

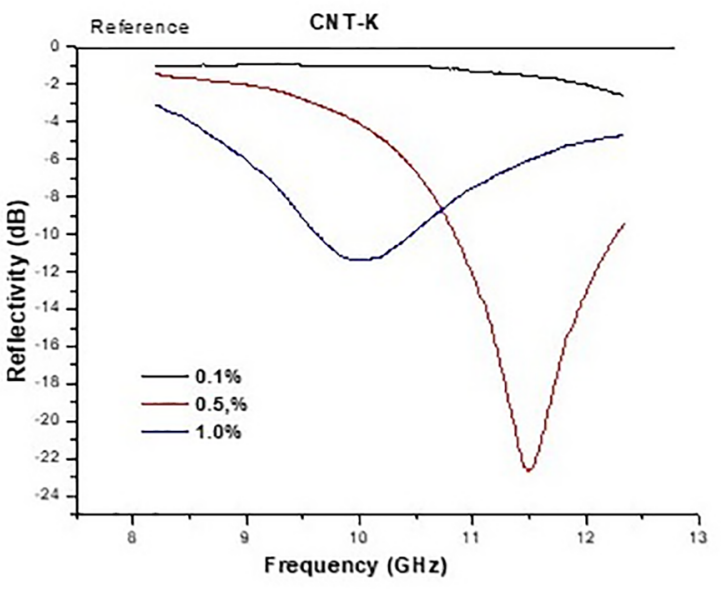

(b)

Figure 7. Reflectivity curves in function of frequency of nanostructured composite containing (a) CNT-B and (b) CNT-K in epoxy resin, with $9 \mathrm{~mm}$-thickness 
condition can not affect the RAM performance if dielectric losses and impedance matching conditions are found. In this sense, a dense CNT interworking network formed can improve the dielectric losses. So, the microwave absorption properties of CNT/epoxy nanocomposites depend on both intrinsic electrical conductivity of CNT and CNT-polymer matrix interactions, as well as the tendency of CNT grouping. These conditions result in polarization phenomena which may result in a good RAM performance ${ }^{33,41}$.

Correlating the reflectivity results with the XRD parameters, it is observed that the CNT-K based nanocomposite present better performance as RAM, despite the lowest structural arrangement of this filler. On the other side, the CNT-K presents the longest length $(10-20 \mu \mathrm{m})$, as informed by the manufacturer ${ }^{14}$. Thus, this characteristic suggests the formation of an interconnected network with the longest CNT in the nanocomposite which promoted better electrical and dielectric losses ${ }^{21}$.

\section{Conclusion}

This work studied the influence of two different multiwalled CNT on RAM performance. XRD analyses showed that the CNT samples presented different structural arrangement, where the longest CNT presented the lowest structural ordering. On the other side, the nanocomposite prepared with the CNT with the best structural ordering showed the worst reflectivity results. This behavior suggests that the longest length of CNT favored the formation of networks more interconnected in the nanocomposite, which promoted adequate electrical and dielectric values, and consequently proper impedance matching to favor the attenuation of the incident wave. In this case, reflectivity results up to $-25 \mathrm{~dB}$ (attenuation values $>99 \%$ ) were measured. Besides the careful preparation of the nanocomposites, SEM analyses show the presence of CNT agglomerates into the nanocomposites, without deleterious effect on RAM performance.

\section{Acknowledgments}

The authors are grateful to CAPES/PVNS and CNPq (Grant $\mathrm{n}^{\circ}$ 303287/2013-6) agencies for the financial supports.

\section{References}

1. Hayashida K, Matsuoka Y. Electromagnetic interference shielding properties of polymer-grafted carbon nanotube composites with high electrical resistance. Carbon. 2015;85:363-371.

2. Dunaevskn GE, Suslyaev VI, Zhuravlev VA, Badin AV, Dorozhkin KV, Kanygin MA, et al. Electromagnetic response of anisotropic polystyrene composite materials containing oriented multiwall carbon nanotubes. In: 2014 39th International Conference on Infrared, Millimeter, and Terahertz waves (IRMMW-THz); 2014 Sep 14; Tucson, AZ, USA.
3. D'Aloia AG, Marra F, Tamburrano A, De Bellis G, Sarto MS. Electromagnetic absorbing properties of graphene-polymer composite shields. Carbon. 2014;73:175-184.

4. Zakharychev EA, Kabina MA, Razov EN, Svetlakov YA, Istomin LA. Effect of functionalization of carbon nanotubes on the radar-absorbing properties of polymeric composites based on them. Russian Journal of Applied Chemistry. 2015;88(2):302307.

5. Sedelnikova OV, Kanygin MA, Korovin EY, Bulusheva LG, Suslyaev VI, Okotrub AV. Effect of fabrication method on the structure and electromagnetic response of carbon nanotube/ polystyrene composites in low-frequency and Ka bands. Composites Science and Technology. 2014;102:59-64.

6. Su J, Zhou W, Liu Y, Qing Y, Luo F, Zhu D. Effect of Carbon Black on Dielectric and Microwave Absorption Properties of Carbon Black/Cordierite Plasma-Sprayed Coatings. Journal of Thermal Spray Technology. 2015;24(5):826-835.

7. Silva VA, Folgueras LC, Cândido GM, de Paula AL, Rezende MC, Costa ML. Nanostructured Composites Based on Carbon Nanotubes and Epoxy Resin for Use as Radar Absorbing Materials. Materials Research. 2013;16(6):1299-1308.

8. Peigney A, Laurent C, Flahaut E, Bacsa RR, Rousset A. Specific surface area of carbon nanotubes and bundles of carbon nanotubes. Carbon. 2001;39(4):507-514.

9. Kotsilkova R, Ivanov E, Bychanok D, Paddubskaya A, Demidenko M, Macutkevic J, et al. Effects of sonochemical modification of carbon nanotubes on electrical and electromagnetic shielding properties of epoxy composites. Composites Science and Technology. 2015;106:85-92.

10. Chakraborty AK, Coleman KS. Poly(ethylene) Glycol/SingleWalled Carbon Nanotube Composites. Journal of Nanoscience and Nanotechnology. 2008;8(8):4013-4016

11. Zhao T, Ji X, Jin W, Guo S, Zhao H, Yang W, et al. Electromagnetic wave absorbing properties of aligned amorphous carbon nanotube/ $\mathrm{BaFe}_{12} \mathrm{O}_{19}$ nanorod composite. Journal of Alloys and Compounds. 2017;703:424-430.

12. Tang N, Zhong W, Au C, Yang Y, Han M, Lin K, et al. Synthesis, Microwave Electromagnetic, and Microwave Absorption Properties of Twin Carbon Nanocoils. The Journal of Physical Chemistry C. 2014;112(49):19316-19323.

13. George N, Chandra J, Mathiazhagan A, Joseph R. High performance natural rubber composites with conductive segregated network of multiwalled carbon nanotubes. Composites Science and Technology. 2015;116:33-40.

14. Baytubes, Product Datasheet. Edition 2009-02-24: https:/ doslide.net/philosophy-of-money.html?utm source $=$ datasheetbaytubes-c-150-phttps://pt.scribd.com/document/77645214/ datasheet-baytubes-c-150-p

15. Hanwha Chemical. Global Networks. CNT \& CNT Application. Available from: $<$ http://hnt.hanwha.co.kr/eng/business/nano_cnt. jsp>. Access in: 28/02/2018.

16. Scherrer P. Bestimmung der Grosse und der Inneren Struktur von Kolloidteilchen Mittels Rontgenstrahlen, Nachrichten von der Gesellschaft der Wissenschaften, Gottingen. MathematischPhysikalische Klasse. 1918;2:98-100. 
17. Agilent Technologies. Agilent Basics of Measuring the Dielectric Properties of Materials. Application Note. Santa Clara: Agilent Technologies; 2006. Available from: \&lt;http://academy.cba.mit. edu/classes/input_devices/meas.pdf\&gt;. Access in: 28/02/2018.

18. Nwigboji IH, Ejembi JI, Wang Z, Bagayoko D, Zhao GL. Microwave absorption properties of multi-walled carbon nanotube (outer diameter 20-30 nm)-epoxy composites from 1 to $26.5 \mathrm{GHz}$. Diamond \& Related Materials. 2015;52:66-71.

19. Sethi J, Sarlin E, Meysami SS, Suihkonen R, Kumar ARSS, Honkanen M, et al. The effect of multi-wall carbon nanotube morphology on electrical and mechanical properties of polyurethane nanocomposites. Composites Part A: Applied Science and Manufacturing. 2017;102:305-313.

20. Li Q, Viereckl A, Rottmair CA, Singer RF. Improved processing of carbon nanotube/magnesium alloy composites. Composites Science and Technology. 2009;69(7-8):1193-1199.

21. Che BD, Nguyen LTT, Nguyen BQ, Nguyen HT, Van Le T, Nguyen NH. Effects of carbon nanotube dispersion methods on the radar absorbing properties of MWCNT/epoxy nanocomposites. Macromolecular Research. 2014;22(11):1221-1228.

22. Mittal, G. et al. A review on carbon nanotubes and graphene as fillers in reinforced polymer nanocomposites. Journal of Industrial and Engineering Chemistry. 2015;(21):11-25.

23. Maa PC, Siddiqui NA, Marom G, Kim JK. Dispersion and functionalization of carbon nanotubes for polymer-based nanocomposites: A review. Composites Part A: Applied Science and Manufacturing. 2010;41(10):1345-1367.

24. Chakraborty AK, Plyhm T, Barbezat M, Necola A, Terrasi GP. Carbon nanotube (CNT)-epoxy nanocomposites: a systematic investigation of CNT dispersion. Journal of Nanoparticle Research. 2011;13(12):6493-6506.

25. Osikoya AO, Wankasi D, Vala RMK, Dikio CW, Afolabi AO, Ayawei N, et al. Synthesis, Characterization and Sorption Studies of Nitrogen-Doped Carbon Nanotubes. Digest Journal of Nanomaterials and Biostructures. 2015;10(1):125-134.

26. Marsh H, Heintz E, Rodriguez-Reinoso F, eds. Introduction to Carbon Technologies. 1st ed. Alicante: University of Alicante; 1997.

27. Fernandez IR. Vibrational Properties of Carbon Nanotubes. [Thesis]. Southampton: University of Southampton, School of Engineering Sciences; 2009.

28. Shen J, Huang W, Wu L, Hu Y, Ye M. Thermo-physical properties of epoxy nanocomposites reinforced with amino functionalized multi-walled carbon nanotubes. Composites Part A: Applied Science and Manufacturing. 2007;38(5):1331-1336.

29. Sun XG, Gao M, Li C, Wu Y. Microwave Absorption Characteristics of Carbon Nanotubes. In: Yellampalli S, ed. Carbon Nanotubes - Synthesis, Characterization, Applications. Rijeka: InTech; 2011.
30. Micheli D, Vricella A, Pastore R, Marchetti M. Synthesis and electromagnetic characterization of frequency selective radar absorbing materials using carbon nanopowders. Carbon. 2014;77:756-774.

31. Pinto SS, Rezende MC. Estudo da aplicação da poli(ometoxianilina) e de seus compósitos com negro de fumo no processamento de absorvedores de micro-ondas. Polímeros. 2012;22(4):325-331.

32. Tiwari DC, Dipak P, Dwivedi SK, Shami TC, Dwivedi P. PPy/ $\mathrm{TiO} 2(\mathrm{np}) / \mathrm{CNT}$ polymer nanocomposite material for microwave absorption. Journal of Materials Science: Materials in Electronics. 2017;29(2):1643-1650.

33. Song YS, Youn JR. Influence of dispersion states of carbon nanotubes on physical properties of epoxy nanocomposites. Carbon. 2005;43(7):1378-1385.

34. Sing BP, Saini K, Choudhary V, Teotia S, Pande S, Saini P, et al. Effect of length of carbon nanotubes on electromagnetic interference shielding and mechanical properties of their reinforced epoxy composites. Journal of Nanoparticle Research. 2014;16:2161.

35. Farukh M, Singh AP, Dhawan SK. Enhanced electromagnetic shielding behavior of multi-walled carbon nanotube entrenched poly (3,4-thylenedioxythiophene) nnanocomposites. Composites Science and Technology. 2015;114:94-102.

36. Singh AP, Mishra M, Hashim DP, Narayanan TN, Hahm MG, Kumar P, et al. Probing the engineered sandwich network of vertically aligned carbon nanotube-reduced graphene oxide composites for high performance electromagnetic interference shielding applications. Carbon. 2015;85:79-88.

37. Al-Saleh MH. Influence of conductive network structure on the EMI shielding and electrical percolation of carbon nanotube/ polymer nanocomposites. Synthetic Metals. 2015;205:78-84.

38. Savi P, Miscuglio M, Giorcelli M, Tagliaferro A. Analysis of Microwave Absorbing Properties of Epoxy MWCNT Composites. Progress In Electromagnetics Research Letters. 2014;44:63-69.

39. Thomassin JM, Jérôme C, Pardoen T, Bailly C, Huynen I, Detrembleur C. Polymer/carbon based composites as electromagnetic interference (EMI) shielding materials. Materials Science and Engineering: R: Reports. 2013;74(7):211-232.

40. Zhao, Hou C, Zhang H, Zhu R, She S, Wang J, et al. Electromagnetic Wave Absorbing Properties of Amorphous Carbon Nanotubes. Scientific Reports. 2014;4:5619.

41. Che BD, Nguyen BQ, Nguyen LTT, Nguyen HT, Nguyen VQ, Le TV, et al. The impact of different multi-walled carbon nanotubes on the X-band microwave absorption of their epoxy nanocomposites. Chemistry Central Journal. 2015;9:10. 